\title{
Alelopatia de espécies vegetais com importância farmacêutica para espécies cultivadas
}

\author{
Grasielle Soares Gusman ${ }^{1}$ \\ Licielo Romero Vieira ${ }^{2}$ \\ Silvane Vestena ${ }^{2 *}$ \\ ${ }^{1}$ Laboratório de Bioquímica, Faculdade de Minas - FAMINAS \\ Avenida Cristiano Ferreira Varella, 655, CEP 368000-000, Muriaé - MG, Brasil \\ ${ }^{2}$ Laboratório de Bioquímica, Universidade Federal do Pampa - UNIPAMPA, \\ Campus São Gabriel Avenida Antônio Trilha, 1847, CEP 97300-000, São Gabriel - RS, Brasil \\ *Autor para correspondência \\ svestena@yahoo.com.br
}

Submetido em 01/02/2012

Aceito para publicação em 06/08/2012

\section{Resumo}

O objetivo deste estudo foi identificar possíveis efeitos alelopáticos de extratos aquosos foliares de Baccharis dracunculifolia DC., Pilocarpus pennatifolius Lem., Cyperus rotundus L., Morus rubra L., Casearia sylvestris Sw. e Plectranthus barbatus Andr. sobre a germinação e o crescimento inicial de Lactuca sativa L., Brassica oleracea L. cv. capitata, B. oleracea L. cv. italica, B. pekinenses L., B. campestris L., Lycopersicum esculentum Miller e Eruca sativa L. Para obtenção dos extratos aquosos foram utilizadas folhas previamente secas na concentração de $1 \mathrm{~g} .10 \mathrm{~mL}^{-1}$, diluída em seis soluções $(10,30,50,70,90$ e 100\%) e comparadas com o controle, água destilada, com cinco repetições de 10 sementes para todas as espécies olerícolas. Os extratos aquosos de todas as espécies evidenciaram potencialidades alelopáticas sobre a germinação das sementes, o índice de velocidade de germinação e o crescimento inicial da parte aérea e do sistema radicular das hortaliças. Os extratos aquosos de C. rotundus e P. barbatus exerceram menores e maiores efeitos alelopáticos, respectivamente, e a estrutura vegetal mais afetada pelos extratos foi a raiz primária. Os resultados indicam a existência de potencial alelopático das espécies testadas, sendo necessários cuidados quando se cultiva hortaliças com elas.

Palavras-chave: Alelopatia; Crescimento inicial; Germinação

\section{Abstract}

Allelopathy of plant species of pharmaceutical importance to cultivated species. This study aimed to identify possible allelopathic effects of leaf aqueous extracts of Baccharis dracunculifolia DC., Pilocarpus pennatifolius Lem., Cyperus rotundus L., Morus rubra L., Casearia sylvestris Sw., and Plectranthus barbatus Andr. on the germination and initial growth of Lactuca sativa L., Brassica oleracea L. cv. capitata, B. oleracea L. cv. italica, B. pekinenses L., B. campestris L., Lycopersicum esculentum Miller, and Eruca sativa L. To obtain the aqueous extracts, leaves previously dried at a $1 \mathrm{~g} .10 \mathrm{~mL}^{-1}$ concentration were used, diluted in six solutions $(10,30,50,70,90$, and $100 \%)$ and compared to control, distilled water, with five replications of 10 seeds for all vegetable species. The aqueous extracts of all species showed allelopathic potential for germination of seeds, the 
germination speed index, and the initial growth of shoots and roots of vegetable crops. The aqueous extracts of $C$. rotundus and $P$. barbatus promoted lower and higher allelopathic effects, respectively, and the vegetal structure mostly affected by the extracts was the primary root. The results indicate the existence of allelopathic potential in the species tested, so there's a need for adopting care procedures when cultivating vegetables with them.

Key words: Allelopathy; Germination; Initial growth

\section{Introdução}

A alelopatia é uma interferência natural pelo qual determinada planta produz substâncias que, quando liberadas no ambiente, podem prejudicar ou estimular outros organismos (ÁQUILA, 2000; WANDSCHEER; PASTORINI, 2008; SOUZA FILHO et al., 2009).

De acordo com a International Allelopathy Society, esse fenômeno pode ser definido como um mecanismo que estuda qualquer processo envolvendo, essencialmente, metabólitos secundários produzidos por plantas, algas, bactérias e fungos, os quais são capazes de influenciar no crescimento e no desenvolvimento de sistemas agrícolas e biológicos. Assim, alelopatia não é uma competição, pois não ocorrem disputas por recursos limitados como luz, água e nutrientes (FERREIRA; ÁQUILA, 2000; DIAS et al., 2005). A alelopatia é, ainda, definida como mecanismo importante a ditar variações na dinâmica da população de plantas, sendo responsável por alterações expressivas na densidade, na diversidade e no desempenho das espécies, o que resulta em alterações na sustentabilidade dos agrossistemas (ÁQUILA, 2000; MARASCHIN-SILVA; ÁQUILA, 2005).

As plantas são capazes de produzir aleloquímicos em todos os seus órgãos e, a concentração em seus tecidos depende de vários fatores como solo, temperatura, luminosidade, pluviosidade, estádio de desenvolvimento, dentre outros (PEREIRA et al., 2008). Sob certas condições, esses compostos são liberados no ambiente, sendo responsáveis por efeitos positivos e negativos no crescimento de outras plantas (KATO-NOGUSHI; INO, 2001). O efeito desses compostos pode ser influenciado pelas características de cada espécie e idade da planta, podendo ser exsudado pelas raízes, pela decomposição dos órgãos da planta ou por meio de chuvas e causando lixiviação desses compostos do extrato superior das plantas para o solo
(RICE, 1984; SARTOR et al., 2009), interferindo na conservação, dormência e germinação das sementes, no crescimento de plântulas e no vigor vegetativo de plantas adultas, podendo também influenciar a competição entre espécies (WANDSCHEER; PASTORINI, 2008). Os aleloquímicos pertencem a determinadas classes de metabólitos secundários, especialmente a de compostos fenólicos (taninos, saponinas, flavonóides, dentre outros) pertencentes às espécies aquáticas e terrestres (BUCHANAN et al., 2000; MACEDO et al., 2007).

Substâncias produzidas pelas plantas ou mesmo por microrganismos podem oferecer novas e excelentes oportunidades para diversificar o controle de plantas daninhas nas culturas, reduzindo ou eliminando a contaminação do ambiente, preservando os recursos naturais e garantindo o oferecimento de produtos agrícolas com alta qualidade, desprovidos de resíduos contaminantes (WANDSCHEER; PASTORINI, 2008; SOUZA FILHO et al., 2009). Além disso, propicia uma alternativa ecologicamente correta no cultivo de plantas para indústria de fitoterápicos (SOUZA FILHO; ALVES, 2002; TUR et al., 2010; SILVA et al., 2011).

Neste contexto, o objetivo do trabalho foi identificar o potencial alelopático de extratos aquosos foliares de alecrim-do-campo (Baccharis dracunculifolia DC.), jaborandi (Pilocarpus pennatifolius Lem.), tiririca (Cyperus rotundus L.), amora (Morus rubra L.), guaçatonga (Casearia sylvestris $\mathrm{Sw}$.) e falso-boldo (Plectranthus barbatus Andr.), sobre a germinação e o crescimento inicial de alface (Lactuca sativa L. cv. grand rapids), repolho (Brassica oleracea L. cv. capitata), brócolis (Brassica oleracea L. cv. italica), couve (Brassica pekinensis L.), mostarda (Brassica campestris L.), tomate (Lycopersicum esculentum Miller) e rúcula (Eruca sativa L.). 


\section{Material e Métodos}

Os experimentos foram conduzidos no Laboratório de Bioquímica da Faculdade de Minas (FAMINAS), Muriaé, MG.

Para a realização dos experimentos foram utilizadas folhas adultas secas de $B$. dracunculifolia, $P$. pennatifolius, $C$. rotundus, $M$. rubra, $C$. sylvestris e $P$. barbatus, obtidas no Município de Muriaé, MG, sendo secas em estufa a $40^{\circ} \mathrm{C}$ até a obtenção de massa seca constante.

Para a obtenção do extrato aquoso das espécies foram utilizadas folhas secas na concentração de $1 \mathrm{~g} 10$ $\mathrm{mL}^{-1}$ (massa/volume) e triturados em um moinho tipo willey. A mistura foi deixada em repouso por 48 horas sob refrigeração $\left(5^{\circ} \pm 1^{\circ} \mathrm{C}\right)$, sendo, após, filtrada em funil-de-büchner, por duas vezes, usando-se papel filtro qualitativo. $\mathrm{O}$ extrato foi diluído em seis concentrações diferentes $(10,30,50,70,90$ e 100\%) e utilizado água destilada como tratamento controle $(0 \%)$, sendo que para a concentração de $100 \%$ foi utilizado o "extrato bruto".

Para a realização dos experimentos de germinação e de crescimento inicial foram utilizadas sementes de repolho, brócolis, couve, alface, rúcula, tomate e mostarda, obtidas no comércio local. Foram efetuados testes preliminares em laboratório para verificação da viabilidade e do vigor da germinação das sementes. Para os testes de germinação foram utilizadas placasde-Petri esterilizadas de $9 \mathrm{~cm}$ de diâmetro, forradas com dois discos de papel-filtro, sendo umedecidas com $7 \mathrm{~mL}$ de água destilada (controle) ou do extrato aquoso. Dez sementes das espécies olerícolas por placa-de-petri com cinco repetições constituíram a unidade experimental. $\mathrm{O}$ experimento foi mantido em câmaras de germinação tipo BOD com temperatura e luminosidade controladas $\left(25 \pm 2^{\circ} \mathrm{C}, 230 \mu\right.$ moles. $\left.\mathrm{m}^{-2} \mathrm{~s}^{-1}\right)$, sob fotoperíodo de $16 / 8$ horas luz/escuro. Foram consideradas germinadas as sementes que apresentaram $2 \mathrm{~mm}$ de protusão radicular (BRASIL, 1992). O experimento foi mantido por um período de 10 dias, sendo verificado diariamente o número de sementes germinadas. Para o crescimento inicial das plântulas, ao final dos 10 dias, foi medido o comprimento, em centímetros, da raiz e da parte aérea, com auxílio de um paquímetro. A determinação do índice de velocidade de germinação (IVG) das sementes foi realizada conforme Maguire (1962), por meio de contagens diárias do número de sementes germinadas.

O delineamento foi inteiramente casualizado sendo os dados submetidos à análise de variância (ANOVA) e as médias, comparadas pelo teste Tukey a $5 \%$ de probabilidade (BEIGUELMAN, 2002).

\section{Resultados e Discussão}

Os extratos aquosos de todas as espécies consideradas alelopáticas reduziram e/ou inibiram a porcentagem de germinação das sementes de todas as hortaliças, exceto para os extratos aquosos de C. rotundus sobre tomate e rúcula. A redução foi proporcional ao aumento das concentrações dos extratos aquosos utilizados (Tabela 1).

Os extratos aquosos de $C$. rotundus e de $C$. sylvestris foram menos efetivos, pois reduziram apenas o percentual de germinação das sementes de hortaliças ao contrário dos extratos de $P$. barbatus que a partir da concentração de 50 ou $70 \%$ inibiram o percentual de germinação da maioria das sementes testadas, sendo os mais efetivos que os demais sobre as espécies de hortaliças (Tabela 1). Ainda, para os demais extratos aquosos, foram observadas reduções e inibições dependendo da espécie cultivada, sendo que quando utilizado os extratos aquosos de M. rubra foi observado inibição no percentual germinativo de alface a partir da concentração de $70 \%$ e de rúcula nas duas concentrações mais elevadas, 90 e 100\% (Tabela 1). Os extratos aquosos de $B$. dracunculifolia e de $P$. pennatifolius apresentaram efeitos alelopáticos na germinação de sementes das hortaliças mais intensos que extratos de $M$. rubra, C. rotundus e C. sylvestris, ocasionando inibição na germinação da maioria das sementes das hortaliças testadas. Extratos aquosos de B. dracunculifolia inibiram a germinação de sementes de alface, repolho, mostarda, couve e rúcula e, extratos aquosos de $P$. pennatifolius inibiram a germinação de sementes de alface, brócolis, mostarda e rúcula; sendo que para as demais espécies foi observado apenas redução do percentual de germinação tanto para extratos de $B$. dracunculifolia como para extratos de P. pennatifolius (Tabela 1). 
TABELA 1: Porcentagem de germinação de sementes de sete hortaliças em extratos aquosos de folhas secas de Baccharis dracunculifolia DC., Pilocarpus pennatifolius Lem., Cyperus rotundus L., Morus rubra L., Casearia sylvestris Sw. e Plectranthus barbatus Andr.

\begin{tabular}{|c|c|c|c|c|c|c|c|c|}
\hline & & \multicolumn{7}{|c|}{ Espécies olerícolas } \\
\hline $\begin{array}{c}\text { Plantas com } \\
\text { potencial } \\
\text { alelopático }\end{array}$ & $\begin{array}{c}\text { Concentração } \\
\text { do extrato } \\
\text { aquoso (\%) }\end{array}$ & $\begin{array}{l}\text { Lactuca } \\
\text { sativa }\end{array}$ & $\begin{array}{c}\text { Brassica } \\
\text { oleracea } \mathrm{cv} \\
\text { capitata }\end{array}$ & $\begin{array}{c}\text { Brassica } \\
\text { oleracea cv } \\
\text { itálica }\end{array}$ & $\begin{array}{c}\text { Brassica } \\
\text { campestris }\end{array}$ & $\begin{array}{c}\text { Brassica } \\
\text { pekinensis }\end{array}$ & $\begin{array}{c}\text { Lycopersicum } \\
\text { esculentum }\end{array}$ & $\begin{array}{l}\text { Eruca } \\
\text { sativa }\end{array}$ \\
\hline \multirow{7}{*}{ 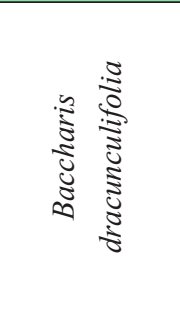 } & 0 & $100 \mathrm{a}$ & $96 \mathrm{a}$ & $100 \mathrm{a}$ & $100 \mathrm{a}$ & $92 \mathrm{a}$ & $96 \mathrm{a}$ & $100 \mathrm{a}$ \\
\hline & 10 & $96 \mathrm{a}$ & $84 \mathrm{a}$ & $84 \mathrm{ab}$ & $100 \mathrm{a}$ & $84 \mathrm{a}$ & $92 \mathrm{a}$ & $100 \mathrm{a}$ \\
\hline & 30 & $92 \mathrm{a}$ & $52 \mathrm{~b}$ & $84 \mathrm{ab}$ & $72 \mathrm{~b}$ & $64 \mathrm{~b}$ & $88 \mathrm{a}$ & $40 \mathrm{~b}$ \\
\hline & 50 & $80 \mathrm{a}$ & $12 \mathrm{c}$ & $84 \mathrm{ab}$ & $0 \mathrm{c}$ & $8 \mathrm{c}$ & $72 a b$ & $4 \mathrm{c}$ \\
\hline & 70 & $80 \mathrm{a}$ & $0 \mathrm{~d}$ & $56 \mathrm{~b}$ & $0 \mathrm{c}$ & $8 \mathrm{c}$ & $44 \mathrm{c}$ & $0 \mathrm{c}$ \\
\hline & 90 & $0 \mathrm{~b}$ & $0 \mathrm{~d}$ & $20 \mathrm{c}$ & $0 \mathrm{c}$ & $0 \mathrm{c}$ & $12 \mathrm{~d}$ & $0 \mathrm{c}$ \\
\hline & 100 & $0 \mathrm{~b}$ & $0 \mathrm{~d}$ & $12 \mathrm{c}$ & $0 \mathrm{c}$ & $0 \mathrm{c}$ & $8 \mathrm{~d}$ & $0 \mathrm{c}$ \\
\hline \multirow{7}{*}{ 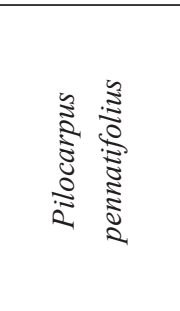 } & 0 & $90 \mathrm{a}$ & $96 \mathrm{a}$ & $100 \mathrm{a}$ & $100 \mathrm{a}$ & $100 \mathrm{a}$ & $100 \mathrm{a}$ & $100 \mathrm{a}$ \\
\hline & 10 & $86 \mathrm{a}$ & $90 \mathrm{a}$ & $74 \mathrm{~b}$ & $100 \mathrm{a}$ & $94 \mathrm{a}$ & $98 \mathrm{a}$ & $54 \mathrm{~b}$ \\
\hline & 30 & $68 \mathrm{~b}$ & $84 \mathrm{ab}$ & $54 \mathrm{~b}$ & $70 \mathrm{~b}$ & $90 \mathrm{ab}$ & $94 \mathrm{a}$ & $48 \mathrm{~b}$ \\
\hline & 50 & $26 \mathrm{c}$ & $72 \mathrm{~b}$ & $12 \mathrm{c}$ & $50 \mathrm{c}$ & $80 \mathrm{~b}$ & $84 a b$ & $20 \mathrm{c}$ \\
\hline & 70 & $0 \mathrm{~d}$ & $72 \mathrm{~b}$ & $0 \mathrm{~d}$ & $22 \mathrm{~d}$ & $62 \mathrm{c}$ & $68 \mathrm{~b}$ & $0 \mathrm{~d}$ \\
\hline & 90 & $0 \mathrm{~d}$ & $52 \mathrm{c}$ & $0 \mathrm{~d}$ & $0 \mathrm{e}$ & $52 \mathrm{c}$ & $18 \mathrm{c}$ & $0 \mathrm{~d}$ \\
\hline & 100 & $0 \mathrm{~d}$ & $52 \mathrm{c}$ & $0 \mathrm{~d}$ & $0 \mathrm{e}$ & $52 \mathrm{c}$ & $18 \mathrm{c}$ & $0 \mathrm{~d}$ \\
\hline \multirow{7}{*}{ 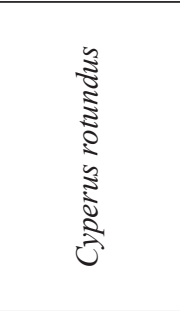 } & 0 & $100 \mathrm{a}$ & $84 \mathrm{a}$ & $88 \mathrm{a}$ & $100 \mathrm{a}$ & $80 \mathrm{a}$ & $92 \mathrm{a}$ & $92 \mathrm{a}$ \\
\hline & 10 & $96 \mathrm{a}$ & $84 \mathrm{a}$ & $88 \mathrm{a}$ & $100 \mathrm{a}$ & $76 \mathrm{a}$ & $92 \mathrm{a}$ & $84 \mathrm{a}$ \\
\hline & 30 & $92 \mathrm{a}$ & $72 a b$ & $88 \mathrm{a}$ & 96 a & $64 \mathrm{ab}$ & $92 \mathrm{a}$ & $80 \mathrm{a}$ \\
\hline & 50 & $92 \mathrm{a}$ & $64 \mathrm{~b}$ & $64 \mathrm{~b}$ & $64 \mathrm{~b}$ & $60 a b$ & $92 \mathrm{a}$ & $80 \mathrm{a}$ \\
\hline & 70 & $92 \mathrm{a}$ & $64 \mathrm{~b}$ & $40 \mathrm{c}$ & $20 \mathrm{c}$ & $32 \mathrm{c}$ & 92 a & $80 \mathrm{a}$ \\
\hline & 90 & $88 \mathrm{ab}$ & $36 \mathrm{c}$ & $40 \mathrm{c}$ & $20 \mathrm{c}$ & $32 \mathrm{c}$ & $92 \mathrm{a}$ & $80 \mathrm{a}$ \\
\hline & 100 & $76 \mathrm{~b}$ & $36 \mathrm{c}$ & $20 \mathrm{~d}$ & $8 \mathrm{c}$ & $12 \mathrm{~d}$ & $84 \mathrm{a}$ & $80 \mathrm{a}$ \\
\hline \multirow{7}{*}{ 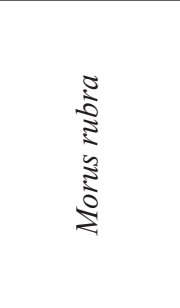 } & 0 & $100 \mathrm{a}$ & $100 \mathrm{a}$ & $92 \mathrm{a}$ & $100 \mathrm{a}$ & $96 \mathrm{a}$ & $94 \mathrm{a}$ & $90 \mathrm{a}$ \\
\hline & 10 & $86 a b$ & $90 \mathrm{a}$ & $82 \mathrm{a}$ & $96 \mathrm{a}$ & $90 \mathrm{a}$ & $88 \mathrm{a}$ & $62 \mathrm{~b}$ \\
\hline & 30 & $50 \mathrm{c}$ & $86 a b$ & $80 \mathrm{ab}$ & $94 \mathrm{a}$ & $82 \mathrm{ab}$ & $68 \mathrm{~b}$ & $42 \mathrm{c}$ \\
\hline & 50 & $22 \mathrm{~d}$ & $70 \mathrm{bc}$ & $70 \mathrm{~b}$ & $82 \mathrm{ab}$ & $66 \mathrm{bc}$ & $60 \mathrm{~b}$ & $38 \mathrm{c}$ \\
\hline & 70 & $0 \mathrm{e}$ & $54 \mathrm{~cd}$ & $48 \mathrm{c}$ & $64 \mathrm{~b}$ & $62 \mathrm{c}$ & $20 \mathrm{c}$ & $2 d$ \\
\hline & 90 & $0 \mathrm{e}$ & $44 \mathrm{~d}$ & $46 \mathrm{c}$ & $14 \mathrm{c}$ & $50 \mathrm{c}$ & $20 \mathrm{c}$ & $0 \mathrm{~d}$ \\
\hline & 100 & $0 \mathrm{e}$ & $22 \mathrm{e}$ & $42 \mathrm{c}$ & $12 \mathrm{c}$ & $30 \mathrm{~d}$ & $6 \mathrm{~d}$ & $0 \mathrm{~d}$ \\
\hline \multirow{7}{*}{ 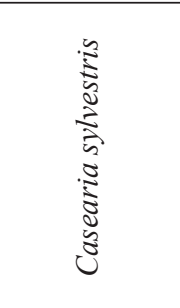 } & 0 & $98 \mathrm{a}$ & $96 \mathrm{a}$ & $92 \mathrm{a}$ & $96 \mathrm{a}$ & $96 \mathrm{a}$ & $94 \mathrm{a}$ & $90 \mathrm{a}$ \\
\hline & 10 & $94 \mathrm{a}$ & $94 \mathrm{a}$ & $88 \mathrm{ab}$ & $92 \mathrm{a}$ & $80 \mathrm{ab}$ & $92 \mathrm{a}$ & $88 \mathrm{a}$ \\
\hline & 30 & $92 \mathrm{a}$ & $90 \mathrm{a}$ & $64 \mathrm{bc}$ & $72 a b$ & $80 a b$ & $90 \mathrm{a}$ & $86 \mathrm{a}$ \\
\hline & 50 & $92 \mathrm{a}$ & $88 \mathrm{a}$ & $56 \mathrm{bc}$ & $72 a b$ & $44 \mathrm{c}$ & $52 \mathrm{~b}$ & $78 \mathrm{ab}$ \\
\hline & 70 & $80 a b$ & $70 \mathrm{ab}$ & $24 \mathrm{~d}$ & $60 \mathrm{~b}$ & $32 \mathrm{c}$ & $38 \mathrm{bc}$ & $38 \mathrm{c}$ \\
\hline & 90 & $44 \mathrm{c}$ & $68 \mathrm{~b}$ & $24 \mathrm{~d}$ & $24 \mathrm{c}$ & $12 \mathrm{~d}$ & $24 \mathrm{c}$ & $4 \mathrm{~d}$ \\
\hline & 100 & $20 \mathrm{~d}$ & $56 \mathrm{~b}$ & $4 \mathrm{e}$ & $16 \mathrm{c}$ & $4 \mathrm{~d}$ & $14 \mathrm{c}$ & $4 \mathrm{~d}$ \\
\hline \multirow{7}{*}{ 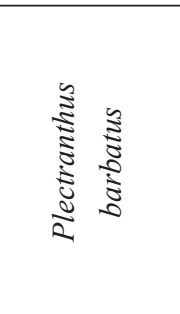 } & 0 & $100 \mathrm{a}$ & $100 \mathrm{a}$ & $100 \mathrm{a}$ & $100 \mathrm{a}$ & $96 \mathrm{a}$ & $100 \mathrm{a}$ & $96 \mathrm{a}$ \\
\hline & 10 & $86 a$ & $90 \mathrm{a}$ & $74 \mathrm{~b}$ & $98 \mathrm{a}$ & $78 a b$ & $86 a b$ & $94 \mathrm{a}$ \\
\hline & 30 & $10 \mathrm{~b}$ & $12 \mathrm{~b}$ & $54 \mathrm{~b}$ & $90 \mathrm{a}$ & $56 \mathrm{~b}$ & $78 \mathrm{~b}$ & $16 \mathrm{~b}$ \\
\hline & 50 & $0 \mathrm{c}$ & $0 \mathrm{c}$ & $12 \mathrm{c}$ & $0 \mathrm{~b}$ & $10 \mathrm{c}$ & $50 \mathrm{c}$ & $10 \mathrm{~b}$ \\
\hline & 70 & $0 \mathrm{c}$ & $0 \mathrm{c}$ & $0 \mathrm{~d}$ & $0 \mathrm{~b}$ & $0 \mathrm{~d}$ & $22 \mathrm{~d}$ & $0 \mathrm{c}$ \\
\hline & 90 & $0 \mathrm{c}$ & $0 \mathrm{c}$ & $0 \mathrm{~d}$ & $0 \mathrm{~b}$ & $0 \mathrm{~d}$ & $0 \mathrm{e}$ & $0 \mathrm{c}$ \\
\hline & 100 & $0 \mathrm{c}$ & $0 \mathrm{c}$ & $0 \mathrm{~d}$ & $0 \mathrm{~b}$ & $0 \mathrm{~d}$ & $0 \mathrm{e}$ & $0 \mathrm{c}$ \\
\hline
\end{tabular}

Médias seguidas pelas mesmas letras nas colunas não diferem significativamente pelo teste Tukey a $5 \%$ de probabilidade. 
Os bioensaios de germinação de sementes na presença de extratos vegetais são pontos de partida para a investigação de efeitos de alelopatia intra e interespecífica, embora haja controvérsia em relação a este tipo de experimento. $\mathrm{O}$ argumento é que as sementes, em decorrência de processos seletivos e evolutivos, são menos sensíveis aos aleloquímicos do que as plântulas (FERREIRA; ÁQUILA, 2000). Entretanto, a germinação não é somente o fenômeno que, em condições adequadas o eixo embrionário prossegue em seu desenvolvimento (CENTENARO et al., 2009). Nesta perspectiva, o crescimento é resultado da germinação, portanto, alterações na fase da germinação poderão originar plântulas com dificuldades de crescimento normal, justificando a redução e/ou inibição da germinação das hortaliças testadas com extratos aquosos das espécies consideradas alelopáticas, exceto em alguns casos para $C$. rotundus sobre sementes de tomate e rúcula e, posterior redução e/ou inibição do crescimento inicial das plântulas. Adicionalmente, nos resultados obtidos, $C$. rotundus foi a única espécie que não ocasionou efeito alelopático na germinação de sementes de rúcula e de tomate, justamente, essa última espécie mais utilizada em bioensaios como indicadora dos efeitos potencialmente alelopáticos, enfatizando-se que a principal vantagem do uso desta espécie como alvo nos estudos alelopáticos está na sensibilidade da espécie, mesmo em baixas concentrações de aleloquímicos.

No presente trabalho, o índice de velocidade de germinação (IVG) de todas as olerícolas foi afetado pelos extratos aquosos de todas as espécies alelopáticas testadas, sendo que para a maioria das espécies olerícolas, independente do extrato utilizado, o IVG foi reduzido a partir da concentração de $10 \%$ ou de $30 \%$, quando comparado ao tratamento controle (Tabela 2), diferindo do ocorrido no processo germinativo; exemplo disso, quando foram testados extratos aquosos de C. rotundus sobre as olerícolas tomate e rúcula, o processo germinativo não sofreu efeito alelopático, ao contrário do observado para o IVG dessas hortaliças, que foi sensível aos extratos desta invasora a partir da concentração de $30 \%$, quando comparado ao tratamento controle (Tabelas 1 e 2 ).

Nos estudos alelopáticos, a germinabilidade (índice final de sementes germinadas) é um índice muito usado, embora não demonstre outros aspectos do processo de germinação, como atrasos, já que envolve apenas resultados finais, ignorando períodos de germinação inativa no decorrer do bioensaio (CHIAPUSIO et al., 1997). Muitas vezes, o que se observa são efeitos significativos de extratos sobre o tempo médio e velocidade de germinação e nenhuma diferença na germinabilidade em relação ao controle (FERREIRA; ÁQUILA, 2000).

Como para a variável percentual de germinação e o IVG, o crescimento inicial do sistema radicular e da parte aérea de todas as hortaliças testadas foi reduzido e/ ou inibido em presença dos extratos aquosos das espécies consideradas alelopáticas, sendo que esta redução foi intensificada com o aumento das concentrações dos extratos aquosos (Tabelas 3 e 4).

Dos extratos aquosos testados, os extratos de $C$. rotundus, foram os que apresentaram menor efeito alelopático no crescimento inicial tanto do sistema radicular como na parte aérea das hortaliças, sendo verificada apenas inibição no crescimento inicial do sistema radicular de mostarda quando utilizado extrato puro, (100\%); para as demais hortaliças foi verificado apenas redução no crescimento inicial tanto da parte aérea como do sistema radicular. Ao contrário dos extratos de C. rotundus, os extratos de P. barbatus, foram mais efetivos, pois inibiram o crescimento inicial das duas estruturas vegetativas a partir da concentração de $30 \%$ para alface e repolho e de $50 \%$ para brócolis, mostarda, couve, tomate e rúcula (Tabelas 3 e 4); assim, com extratos aquosos dessas duas espécies, este resultado observado sobre o crescimento segue o mesmo padrão para o percentual de germinação (Tabelas 1, 3 e 4).

Os extratos aquosos de B. dracunculifolia inibiram o crescimento de todas as espécies de hortaliças, sendo que algumas foram mais afetadas, principalmente, o sistema radicular de repolho. Ao contrário do observado para esta espécie, o crescimento das duas partes vegetativas de todas as hortaliças testadas foi, também, inibido quando em presença de extratos de $P$. pennatifolius, exceto para o repolho, onde foi observado apenas redução no crescimento inicial do sistema radicular e da parte aérea. 
TABELA 2: Índice de velocidade de germinação (IVG) de sete hortaliças em extratos aquosos de folhas secas de Baccharis dracunculifolia DC., Pilocarpus pennatifolius Lem., Cyperus rotundus L., Morus rubra L., Casearia sylvestris Sw. e Plectranthus barbatus Andr.

\begin{tabular}{|c|c|c|c|c|c|c|c|c|}
\hline & & \multicolumn{7}{|c|}{ Espécies olerícolas } \\
\hline $\begin{array}{c}\text { Plantas com } \\
\text { potencial } \\
\text { alelopático }\end{array}$ & $\begin{array}{c}\text { Concentração } \\
\text { do extrato } \\
\text { aquoso (\%) }\end{array}$ & $\begin{array}{c}\text { Lactuca } \\
\text { sativa }\end{array}$ & $\begin{array}{c}\text { Brassica } \\
\text { oleracea cv } \\
\text { capitata }\end{array}$ & $\begin{array}{c}\text { Brassica } \\
\text { oleracea cv } \\
\text { itálica }\end{array}$ & $\begin{array}{c}\text { Brassica } \\
\text { campestris }\end{array}$ & $\begin{array}{c}\text { Brassica } \\
\text { pekinensis }\end{array}$ & $\begin{array}{l}\text { Lycopersicum } \\
\text { esculentum }\end{array}$ & $\begin{array}{l}\text { Eruca } \\
\text { sativa }\end{array}$ \\
\hline \multirow{7}{*}{ 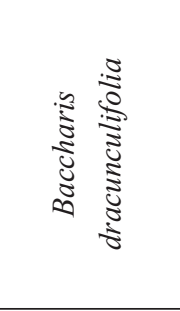 } & 0 & $8,9 \mathrm{a}$ & $5,2 \mathrm{a}$ & $9,4 \mathrm{a}$ & $9,5 \mathrm{a}$ & $9,3 \mathrm{a}$ & $3,7 \mathrm{a}$ & $8,1 \mathrm{a}$ \\
\hline & 10 & $8,7 \mathrm{a}$ & $4,5 \mathrm{a}$ & $7,0 \mathrm{~b}$ & $5,2 \mathrm{~b}$ & $6,7 \mathrm{~b}$ & $2,0 \mathrm{ab}$ & $3,8 \mathrm{~b}$ \\
\hline & 30 & $3,6 \mathrm{~b}$ & $2,4 \mathrm{~b}$ & $3,1 \mathrm{c}$ & $3,0 \mathrm{c}$ & $3,5 \mathrm{c}$ & $1,2 b c$ & $0,7 \mathrm{c}$ \\
\hline & 50 & $2,9 \mathrm{~b}$ & $0,2 \mathrm{c}$ & $2,5 \mathrm{c}$ & $0,0 \mathrm{~d}$ & $2,8 \mathrm{c}$ & $0,9 \mathrm{c}$ & $0,2 \mathrm{~d}$ \\
\hline & 70 & $2,6 \mathrm{~b}$ & $0,0 \mathrm{c}$ & $1,2 \mathrm{~d}$ & $0,0 \mathrm{~d}$ & $1,2 \mathrm{~d}$ & $0,5 \mathrm{c}$ & $0,0 \mathrm{~d}$ \\
\hline & 90 & $0,0 \mathrm{c}$ & $0,0 \mathrm{c}$ & $0,5 \mathrm{e}$ & $0,0 \mathrm{~d}$ & $0,0 \mathrm{e}$ & $0,2 \mathrm{~d}$ & $0,0 \mathrm{~d}$ \\
\hline & 100 & $0,0 \mathrm{c}$ & $0,0 \mathrm{c}$ & $0,5 \mathrm{e}$ & $0,0 \mathrm{~d}$ & $0,0 \mathrm{e}$ & $0,2 \mathrm{~d}$ & $0,0 \mathrm{~d}$ \\
\hline \multirow{7}{*}{ 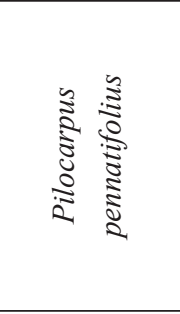 } & 0 & $7,7 \mathrm{a}$ & $9,6 \mathrm{a}$ & $9,1 \mathrm{a}$ & $8,8 \mathrm{a}$ & $9,7 \mathrm{a}$ & $9,4 \mathrm{a}$ & $7,8 \mathrm{a}$ \\
\hline & 10 & $5,0 \mathrm{~b}$ & $9,3 \mathrm{a}$ & $4,8 \mathrm{~b}$ & $6,2 \mathrm{~b}$ & $9,2 \mathrm{a}$ & $9,0 \mathrm{a}$ & $5,1 \mathrm{~b}$ \\
\hline & 30 & $4,2 \mathrm{c}$ & $6,0 \mathrm{~b}$ & $4,7 \mathrm{~b}$ & $6,0 \mathrm{~b}$ & $6,5 \mathrm{~b}$ & $7,1 \mathrm{~b}$ & $4,8 \mathrm{bc}$ \\
\hline & 50 & $3,4 \mathrm{~d}$ & $4,3 \mathrm{c}$ & $3,3 \mathrm{c}$ & $5,3 \mathrm{~b}$ & $4,0 \mathrm{c}$ & $6,8 \mathrm{~b}$ & $4,0 \mathrm{c}$ \\
\hline & 70 & $0,0 \mathrm{e}$ & $2,9 \mathrm{~d}$ & $0,0 \mathrm{~d}$ & $3,0 \mathrm{c}$ & $3,8 \mathrm{c}$ & $4,3 \mathrm{c}$ & $0,0 \mathrm{~d}$ \\
\hline & 90 & $0,0 \mathrm{e}$ & $2,2 \mathrm{~d}$ & $0,0 \mathrm{~d}$ & $0,0 \mathrm{~d}$ & $2,0 \mathrm{~d}$ & $2,5 \mathrm{~d}$ & $0,0 \mathrm{~d}$ \\
\hline & 100 & $0,0 \mathrm{e}$ & $1,2 \mathrm{e}$ & $0,0 \mathrm{~d}$ & $0,0 \mathrm{~d}$ & $1,6 \mathrm{~d}$ & $2,1 \mathrm{~d}$ & $0,0 \mathrm{~d}$ \\
\hline \multirow{7}{*}{ 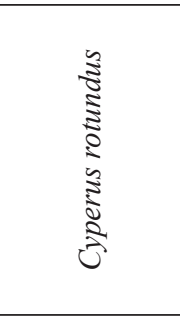 } & 0 & $8,8 \mathrm{a}$ & $8,5 \mathrm{a}$ & $9,8 \mathrm{a}$ & $9,2 \mathrm{a}$ & $7,5 \mathrm{a}$ & $9,8 \mathrm{a}$ & $8,2 \mathrm{a}$ \\
\hline & 10 & $8,5 \mathrm{a}$ & $8,1 \mathrm{a}$ & $9,5 \mathrm{a}$ & $9,0 \mathrm{a}$ & $6,6 \mathrm{a}$ & $8,8 \mathrm{a}$ & $7,8 \mathrm{a}$ \\
\hline & 30 & $6,9 \mathrm{~b}$ & $6,2 \mathrm{~b}$ & $5,9 \mathrm{~b}$ & $5,2 \mathrm{~b}$ & $6,4 \mathrm{a}$ & $5,5 \mathrm{~b}$ & $4,4 \mathrm{~b}$ \\
\hline & 50 & $6,1 \mathrm{~b}$ & $2,8 \mathrm{c}$ & $5,1 \mathrm{bc}$ & $5,1 \mathrm{~b}$ & $3,1 \mathrm{~b}$ & $2,5 \mathrm{c}$ & $4,0 \mathrm{~b}$ \\
\hline & 70 & $5,0 \mathrm{c}$ & $2,6 \mathrm{c}$ & $4,5 \mathrm{c}$ & $4,8 \mathrm{~b}$ & $3,0 \mathrm{~b}$ & $2,3 \mathrm{c}$ & $3,9 \mathrm{~b}$ \\
\hline & 90 & $4,0 \mathrm{~d}$ & $2,5 \mathrm{c}$ & $4,0 \mathrm{~cd}$ & $4,1 \mathrm{~b}$ & $2,5 \mathrm{bc}$ & $20 \mathrm{c}$ & $2,4 \mathrm{c}$ \\
\hline & 100 & $3,8 \mathrm{~d}$ & $2,3 \mathrm{c}$ & $3,2 \mathrm{~d}$ & $2,4 \mathrm{c}$ & $1,8 \mathrm{c}$ & $2,0 \mathrm{c}$ & $2,3 \mathrm{c}$ \\
\hline \multirow{7}{*}{ 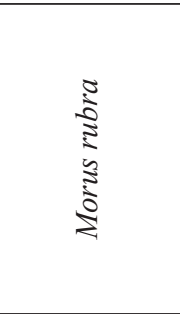 } & 0 & $7,7 \mathrm{a}$ & $8,6 \mathrm{a}$ & $8,1 \mathrm{a}$ & $9,8 \mathrm{a}$ & $9,3 \mathrm{a}$ & $9,4 \mathrm{a}$ & $7,8 \mathrm{a}$ \\
\hline & 10 & $5,0 \mathrm{~b}$ & $8,3 \mathrm{a}$ & $5,8 \mathrm{~b}$ & $7,2 \mathrm{~b}$ & $8,8 \mathrm{a}$ & $9,0 \mathrm{a}$ & $5,1 \mathrm{~b}$ \\
\hline & 30 & $4,2 \mathrm{c}$ & $7,0 \mathrm{~b}$ & $4,7 \mathrm{~b}$ & $7,0 \mathrm{~b}$ & $5,5 \mathrm{~b}$ & $7,1 \mathrm{~b}$ & $4,8 \mathrm{bc}$ \\
\hline & 50 & $3,4 \mathrm{~d}$ & $5,3 \mathrm{c}$ & $3,3 \mathrm{c}$ & $6,3 \mathrm{~b}$ & $4,0 \mathrm{c}$ & $6,8 \mathrm{~b}$ & $4,0 \mathrm{c}$ \\
\hline & 70 & $0,0 \mathrm{e}$ & $4,1 \mathrm{~d}$ & $3,0 \mathrm{c}$ & $4,0 \mathrm{c}$ & $3,8 \mathrm{c}$ & $4,3 \mathrm{c}$ & $3,8 \mathrm{c}$ \\
\hline & 90 & $0,0 \mathrm{e}$ & $2,8 \mathrm{e}$ & $2,5 \mathrm{~cd}$ & $2,4 \mathrm{c}$ & $3,3 \mathrm{~cd}$ & $3,9 \mathrm{c}$ & $0,0 \mathrm{~d}$ \\
\hline & 100 & $0,0 \mathrm{e}$ & $1,2 \mathrm{f}$ & $1,8 \mathrm{~d}$ & $1,3 \mathrm{~d}$ & $2,6 \mathrm{~d}$ & $2,1 \mathrm{~d}$ & $0,0 \mathrm{~d}$ \\
\hline \multirow{7}{*}{ 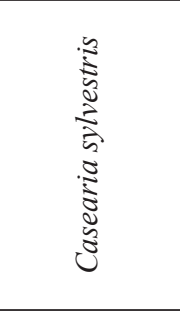 } & 0 & $7,0 \mathrm{a}$ & $5,2 \mathrm{a}$ & $2,6 \mathrm{a}$ & $7,3 \mathrm{a}$ & $8,5 \mathrm{a}$ & $3,5 \mathrm{a}$ & $8,3 \mathrm{a}$ \\
\hline & 10 & $6,1 \mathrm{a}$ & $4,8 \mathrm{a}$ & $2,6 \mathrm{a}$ & $7,2 \mathrm{a}$ & $7,8 \mathrm{a}$ & $3,0 \mathrm{a}$ & $7,7 \mathrm{a}$ \\
\hline & 30 & $6,0 \mathrm{a}$ & $1,4 \mathrm{~b}$ & $1,0 \mathrm{~b}$ & $6,4 \mathrm{a}$ & $7,7 \mathrm{a}$ & $0,8 \mathrm{~b}$ & $2,6 \mathrm{~b}$ \\
\hline & 50 & $2,0 \mathrm{~b}$ & $1,0 \mathrm{~b}$ & $0,7 \mathrm{~b}$ & $2,7 \mathrm{~b}$ & $3,7 \mathrm{~b}$ & $0,6 \mathrm{bc}$ & $2,2 \mathrm{~b}$ \\
\hline & 70 & $1,6 \mathrm{~b}$ & $0,9 \mathrm{~b}$ & $0,7 \mathrm{~b}$ & $2,0 \mathrm{~b}$ & $3,1 \mathrm{~b}$ & $0,6 \mathrm{bc}$ & $2,2 \mathrm{~b}$ \\
\hline & 90 & $0,7 \mathrm{c}$ & $0,4 \mathrm{c}$ & $0,6 \mathrm{~b}$ & $1,8 \mathrm{~b}$ & $1,0 \mathrm{c}$ & $0,5 \mathrm{bc}$ & $1,9 \mathrm{bc}$ \\
\hline & 100 & $0,5 \mathrm{c}$ & $0,3 \mathrm{c}$ & $0,2 \mathrm{c}$ & $0,9 \mathrm{c}$ & $0,9 \mathrm{c}$ & $0,4 \mathrm{c}$ & $1,5 \mathrm{c}$ \\
\hline \multirow{7}{*}{ 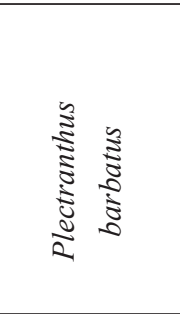 } & 0 & $9,2 \mathrm{a}$ & $8,9 \mathrm{a}$ & $9,6 \mathrm{a}$ & $9,6 \mathrm{a}$ & $7,5 \mathrm{a}$ & $8,8 \mathrm{a}$ & $9,7 \mathrm{a}$ \\
\hline & 10 & $7,5 \mathrm{~b}$ & $8,7 \mathrm{a}$ & $8,0 \mathrm{~b}$ & $7,5 \mathrm{~b}$ & $4,6 \mathrm{~b}$ & $6,5 \mathrm{~b}$ & $7,3 \mathrm{~b}$ \\
\hline & 30 & $6,4 \mathrm{~b}$ & $7,6 \mathrm{~b}$ & $8,0 \mathrm{~b}$ & $2,8 \mathrm{c}$ & $2,5 \mathrm{c}$ & $4,1 \mathrm{c}$ & $4,5 \mathrm{c}$ \\
\hline & 50 & $0,0 \mathrm{c}$ & $0,0 \mathrm{c}$ & $5,0 \mathrm{c}$ & $0,0 \mathrm{~d}$ & $1,8 \mathrm{c}$ & $2,3 \mathrm{~d}$ & $1,5 \mathrm{~d}$ \\
\hline & 70 & $0,0 \mathrm{c}$ & $0,0 \mathrm{c}$ & $0,0 \mathrm{~d}$ & $0,0 \mathrm{~d}$ & $0,0 \mathrm{~d}$ & $2,0 \mathrm{~d}$ & $0,0 \mathrm{e}$ \\
\hline & 90 & $0,0 \mathrm{c}$ & $0,0 \mathrm{c}$ & $0,0 \mathrm{~d}$ & $0,0 \mathrm{~d}$ & $0,0 \mathrm{~d}$ & $0,0 \mathrm{e}$ & $0,0 \mathrm{e}$ \\
\hline & 100 & $0,0 \mathrm{c}$ & $0,0 \mathrm{c}$ & $0,0 \mathrm{~d}$ & $0,0 \mathrm{~d}$ & $0,0 \mathrm{~d}$ & $0,0 \mathrm{e}$ & $0,0 \mathrm{e}$ \\
\hline
\end{tabular}

Médias seguidas pelas mesmas letras nas colunas não diferem significativamente pelo teste Tukey a $5 \%$ de probabilidade. 
TABELA 3: Comprimento da raiz ( $\mathrm{cm}$ ) de sete hortaliças em extratos aquosos de folhas secas de Baccharis dracunculifolia DC., Pilocarpus pennatifolius Lem., Cyperus rotundus L., Morus rubra L., Casearia sylvestris Sw. e Plectranthus barbatus Andr.

\begin{tabular}{|c|c|c|c|c|c|c|c|c|}
\hline & & \multicolumn{7}{|c|}{ Espécies olerícolas } \\
\hline $\begin{array}{c}\text { Plantas com } \\
\text { potencial } \\
\text { alelopático }\end{array}$ & $\begin{array}{c}\text { Concentração } \\
\text { do extrato } \\
\text { aquoso (\%) }\end{array}$ & $\begin{array}{l}\text { Lactuca } \\
\text { sativa }\end{array}$ & $\begin{array}{c}\text { Brassica } \\
\text { oleracea cv } \\
\text { capitata }\end{array}$ & $\begin{array}{l}\text { Brassica } \\
\text { oleracea } \\
\text { cv itálica }\end{array}$ & $\begin{array}{c}\text { Brassica } \\
\text { campestris }\end{array}$ & $\begin{array}{c}\text { Brassica } \\
\text { pekinensis }\end{array}$ & $\begin{array}{l}\text { Lycopersicum } \\
\text { esculentum }\end{array}$ & $\begin{array}{l}\text { Eruca } \\
\text { sativa }\end{array}$ \\
\hline \multirow{7}{*}{ 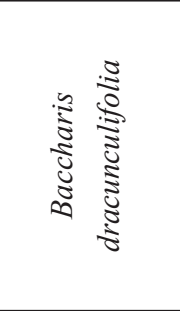 } & 0 & $1,9 \mathrm{a}$ & $1,6 \mathrm{a}$ & $5,6 \mathrm{a}$ & $6,0 \mathrm{a}$ & $5,3 \mathrm{a}$ & $8,0 \mathrm{a}$ & $3,5 \mathrm{a}$ \\
\hline & 10 & $1,4 \mathrm{~b}$ & $0,5 \mathrm{~b}$ & $3,7 \mathrm{~b}$ & $3,8 \mathrm{~b}$ & $4,6 \mathrm{a}$ & $3,9 \mathrm{~b}$ & $2,3 \mathrm{a}$ \\
\hline & 30 & $0,2 \mathrm{c}$ & $0,0 \mathrm{c}$ & $0,5 \mathrm{c}$ & $1,1 \mathrm{c}$ & $0,6 \mathrm{~b}$ & $1,0 \mathrm{c}$ & $0,2 \mathrm{~b}$ \\
\hline & 50 & $0,1 \mathrm{c}$ & $0,0 \mathrm{c}$ & $0,3 \mathrm{~cd}$ & $0,0 \mathrm{~d}$ & $0,0 \mathrm{c}$ & $0,4 \mathrm{~d}$ & $0,0 \mathrm{~b}$ \\
\hline & 70 & $0,1 \mathrm{c}$ & $0,0 \mathrm{c}$ & $0,2 \mathrm{~d}$ & $0,0 \mathrm{~d}$ & $0,0 \mathrm{c}$ & $0,2 \mathrm{de}$ & $0,0 \mathrm{~b}$ \\
\hline & 90 & $0,0 \mathrm{c}$ & $0,0 \mathrm{c}$ & $0,0 \mathrm{~d}$ & $0,0 \mathrm{~d}$ & $0,0 \mathrm{c}$ & $0,1 \mathrm{e}$ & $0,0 \mathrm{~b}$ \\
\hline & 100 & $0,0 \mathrm{c}$ & $0,0 \mathrm{c}$ & $0,0 \mathrm{~d}$ & $0,0 \mathrm{~d}$ & $0,0 \mathrm{c}$ & $0,0 \mathrm{e}$ & $0,0 \mathrm{~b}$ \\
\hline \multirow{7}{*}{ 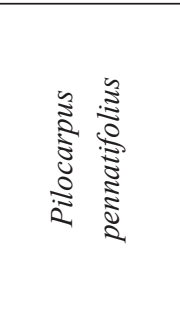 } & 0 & $2,6 \mathrm{a}$ & $5,4 \mathrm{a}$ & $5,2 \mathrm{a}$ & $4,5 \mathrm{a}$ & $4,2 \mathrm{a}$ & $4,5 \mathrm{a}$ & $2,3 \mathrm{a}$ \\
\hline & 10 & $27 \mathrm{a}$ & $4,0 \mathrm{~b}$ & $4,5 \mathrm{a}$ & $4,1 \mathrm{a}$ & $3,5 \mathrm{a}$ & $3,7 \mathrm{a}$ & $2,2 \mathrm{a}$ \\
\hline & 30 & $0,2 \mathrm{~b}$ & $2,9 \mathrm{c}$ & $0,3 \mathrm{~b}$ & $3,4 \mathrm{~b}$ & $0,5 \mathrm{~b}$ & $2,5 \mathrm{~b}$ & $0,6 \mathrm{~b}$ \\
\hline & 50 & $0,0 \mathrm{~b}$ & $1,9 \mathrm{~d}$ & $0,0 \mathrm{~b}$ & $1,0 \mathrm{c}$ & $0,0 \mathrm{c}$ & $2,0 \mathrm{bc}$ & $0,0 \mathrm{c}$ \\
\hline & 70 & $0,0 \mathrm{~b}$ & $0,7 \mathrm{e}$ & $0,0 \mathrm{~b}$ & $0,4 \mathrm{~d}$ & $0,0 \mathrm{c}$ & $1,6 \mathrm{c}$ & $0,0 \mathrm{c}$ \\
\hline & 90 & $0,0 \mathrm{~b}$ & $0,2 \mathrm{f}$ & $0,0 \mathrm{~b}$ & $0,0 \mathrm{e}$ & $0,0 \mathrm{c}$ & $0,0 \mathrm{~d}$ & $0,0 \mathrm{c}$ \\
\hline & 100 & $0,0 \mathrm{~b}$ & $0,2 \mathrm{f}$ & $0,0 \mathrm{~b}$ & $0,0 \mathrm{e}$ & $0,0 \mathrm{c}$ & $0,0 \mathrm{~d}$ & $0,0 \mathrm{c}$ \\
\hline \multirow{7}{*}{ 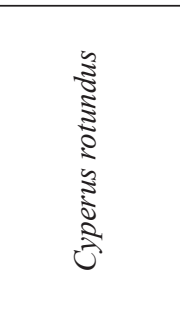 } & 0 & $4,6 \mathrm{a}$ & $5,2 \mathrm{a}$ & $4,2 \mathrm{a}$ & $4,3 \mathrm{a}$ & $4,8 \mathrm{a}$ & $8,9 \mathrm{a}$ & $2,9 \mathrm{a}$ \\
\hline & 10 & $3,3 \mathrm{~b}$ & $4,6 \mathrm{a}$ & $4,1 \mathrm{a}$ & $4,2 \mathrm{a}$ & $4,3 \mathrm{a}$ & $6,5 a b$ & $1,4 \mathrm{~b}$ \\
\hline & 30 & $2,8 \mathrm{~b}$ & $3,5 \mathrm{~b}$ & $3,7 \mathrm{a}$ & $4,3 \mathrm{a}$ & $3,7 \mathrm{a}$ & $5,5 \mathrm{~b}$ & $1,0 \mathrm{~b}$ \\
\hline & 50 & $2,0 \mathrm{c}$ & $2,2 \mathrm{c}$ & $1,6 \mathrm{~b}$ & $2,4 \mathrm{~b}$ & $1,3 \mathrm{~b}$ & $5,3 \mathrm{~b}$ & $0,9 \mathrm{~b}$ \\
\hline & 70 & $1,4 \mathrm{~d}$ & $1,8 \mathrm{c}$ & $0,4 \mathrm{c}$ & $0,4 \mathrm{c}$ & $0,5 \mathrm{c}$ & $4,4 \mathrm{bc}$ & $1,0 \mathrm{~b}$ \\
\hline & 90 & $0,7 \mathrm{e}$ & $0,3 \mathrm{~d}$ & $0,4 \mathrm{c}$ & $0,4 \mathrm{c}$ & $0,4 \mathrm{c}$ & $4,2 \mathrm{bc}$ & $0,9 \mathrm{~b}$ \\
\hline & 100 & $0,5 \mathrm{e}$ & $0,3 \mathrm{~d}$ & $0,1 \mathrm{~d}$ & $0,0 \mathrm{~d}$ & $0,1 \mathrm{~d}$ & $3,1 \mathrm{c}$ & $1,0 \mathrm{~b}$ \\
\hline \multirow{7}{*}{ 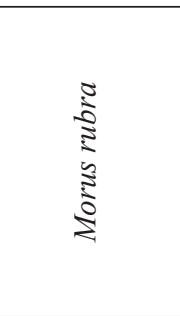 } & 0 & $1,5 \mathrm{a}$ & $5,4 \mathrm{a}$ & $5,2 \mathrm{a}$ & $4,9 \mathrm{a}$ & $5,7 \mathrm{a}$ & $4,7 \mathrm{a}$ & $2,3 \mathrm{a}$ \\
\hline & 10 & $1,4 \mathrm{a}$ & $5,2 \mathrm{a}$ & $2,3 \mathrm{~b}$ & $4,8 \mathrm{a}$ & $3,6 \mathrm{~b}$ & $2,2 \mathrm{~b}$ & $0,9 \mathrm{~b}$ \\
\hline & 30 & $0,4 \mathrm{~b}$ & $2,6 \mathrm{~b}$ & $2,1 \mathrm{~b}$ & $2,0 \mathrm{~b}$ & $1,5 \mathrm{c}$ & $1,4 \mathrm{c}$ & $0,3 \mathrm{c}$ \\
\hline & 50 & $0,2 \mathrm{bc}$ & $1,0 \mathrm{c}$ & $0,5 \mathrm{c}$ & $1,0 \mathrm{c}$ & $0,5 \mathrm{~d}$ & $1,3 \mathrm{c}$ & $0,0 \mathrm{c}$ \\
\hline & 70 & $0,0 \mathrm{c}$ & $0,2 \mathrm{~d}$ & $0,5 \mathrm{c}$ & $0,3 \mathrm{~d}$ & $0,2 \mathrm{e}$ & $0,2 \mathrm{~d}$ & $0,0 \mathrm{c}$ \\
\hline & 90 & $0,0 \mathrm{c}$ & $0,2 \mathrm{~d}$ & $0,1 \mathrm{~d}$ & $0,0 \mathrm{~d}$ & $0,0 \mathrm{e}$ & $0,2 \mathrm{~d}$ & $0,0 \mathrm{c}$ \\
\hline & 100 & $0,0 \mathrm{c}$ & $0,2 \mathrm{~d}$ & $0,1 \mathrm{~d}$ & $0,0 \mathrm{~d}$ & $0,0 \mathrm{e}$ & $0,0 \mathrm{~d}$ & $0,0 \mathrm{c}$ \\
\hline \multirow{7}{*}{  } & 0 & $4,5 \mathrm{a}$ & $7,5 \mathrm{a}$ & $3,2 \mathrm{a}$ & $5,6 \mathrm{a}$ & $5,5 \mathrm{a}$ & $9,7 \mathrm{a}$ & $3,3 \mathrm{a}$ \\
\hline & 10 & $2,8 \mathrm{~b}$ & $7,4 \mathrm{a}$ & $3,2 \mathrm{a}$ & $4,9 \mathrm{a}$ & $4,0 \mathrm{ab}$ & $4,7 \mathrm{~b}$ & $3,0 \mathrm{a}$ \\
\hline & 30 & $1,8 \mathrm{~b}$ & $2,9 \mathrm{~b}$ & $0,3 \mathrm{~b}$ & $1,6 \mathrm{~b}$ & $1,3 \mathrm{c}$ & $4,7 \mathrm{~b}$ & $1,5 \mathrm{~b}$ \\
\hline & 50 & $1,8 \mathrm{~b}$ & $0,6 \mathrm{c}$ & $0,0 \mathrm{~b}$ & $0,0 \mathrm{c}$ & $0,2 \mathrm{~d}$ & $1,5 \mathrm{c}$ & $0,3 \mathrm{c}$ \\
\hline & 70 & $0,8 \mathrm{c}$ & $0,2 \mathrm{~d}$ & $0,0 \mathrm{~b}$ & $0,0 \mathrm{c}$ & $0,0 \mathrm{~d}$ & $0,3 \mathrm{~d}$ & $0,2 \mathrm{c}$ \\
\hline & 90 & $0,4 \mathrm{~d}$ & $0,1 \mathrm{~d}$ & $0,0 \mathrm{~b}$ & $0,0 \mathrm{c}$ & $0,0 \mathrm{~d}$ & $0,3 \mathrm{~d}$ & $0,0 \mathrm{c}$ \\
\hline & 100 & $0,2 \mathrm{~d}$ & $0,0 \mathrm{~d}$ & $0,0 \mathrm{~b}$ & $0,0 \mathrm{c}$ & $0,0 \mathrm{~d}$ & $0,3 \mathrm{~d}$ & $0,0 \mathrm{c}$ \\
\hline \multirow{7}{*}{ 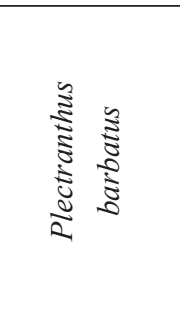 } & 0 & $1,5 \mathrm{a}$ & $3,7 \mathrm{a}$ & $2,4 \mathrm{a}$ & $3,6 \mathrm{a}$ & $2,5 \mathrm{a}$ & $5,6 \mathrm{a}$ & $2,9 \mathrm{a}$ \\
\hline & 10 & $1,4 \mathrm{a}$ & $2,6 \mathrm{~b}$ & $1,3 \mathrm{~b}$ & $3,3 \mathrm{a}$ & $2,5 \mathrm{a}$ & $4,3 \mathrm{~b}$ & $2,9 \mathrm{a}$ \\
\hline & 30 & $0,0 \mathrm{~b}$ & $0,0 \mathrm{c}$ & $0,0 \mathrm{c}$ & $1,4 \mathrm{~b}$ & $0,2 \mathrm{~b}$ & $1,7 \mathrm{c}$ & $0,1 \mathrm{~b}$ \\
\hline & 50 & $0,0 \mathrm{~b}$ & $0,0 \mathrm{c}$ & $0,0 \mathrm{c}$ & $0,0 \mathrm{c}$ & $0,0 \mathrm{~b}$ & $0,0 \mathrm{~d}$ & $0,0 \mathrm{~b}$ \\
\hline & 70 & $0,0 \mathrm{~b}$ & $0,0 \mathrm{c}$ & $0,0 \mathrm{c}$ & $0,0 \mathrm{c}$ & $0,0 \mathrm{~b}$ & $0,0 \mathrm{~d}$ & $0,0 \mathrm{~b}$ \\
\hline & 90 & $0,0 \mathrm{~b}$ & $0,0 \mathrm{c}$ & $0,0 \mathrm{c}$ & $0,0 \mathrm{c}$ & $0,0 \mathrm{~b}$ & $0,0 \mathrm{~d}$ & $0,0 \mathrm{~b}$ \\
\hline & 100 & $0,0 \mathrm{~b}$ & $0,0 \mathrm{c}$ & $0,0 \mathrm{c}$ & $0,0 \mathrm{c}$ & $0,0 \mathrm{~b}$ & $0,0 \mathrm{~d}$ & $0,0 \mathrm{~b}$ \\
\hline
\end{tabular}

Médias \pm desvio padrão seguidas pelas mesmas letras nas colunas não diferem significativamente pelo teste Tukey a $5 \%$ de probabilidade. 
TABELA 4: Comprimento da parte aérea $(\mathrm{cm})$ de sete hortaliças em extratos aquosos de folhas secas de Baccharis dracunculifolia DC., Pilocarpus pennatifolius Lem., Cyperus rotundus L., Morus rubra L., Casearia sylvestris Sw. e Plectranthus barbatus Andr.

\begin{tabular}{|c|c|c|c|c|c|c|c|c|}
\hline \multicolumn{9}{|c|}{ Espécies olerícolas } \\
\hline $\begin{array}{c}\text { Plantas com } \\
\text { potencial } \\
\text { alelopático }\end{array}$ & $\begin{array}{c}\text { Concentração } \\
\text { do extrato } \\
\text { aquoso (\%) }\end{array}$ & $\begin{array}{l}\text { Lactuca } \\
\text { sativa }\end{array}$ & $\begin{array}{c}\text { Brassica } \\
\text { oleracea cv } \\
\text { capitata }\end{array}$ & $\begin{array}{c}\text { Brassica } \\
\text { oleracea cv } \\
\text { itálica }\end{array}$ & $\begin{array}{c}\text { Brassica } \\
\text { campestris }\end{array}$ & $\begin{array}{c}\text { Brassica } \\
\text { pekinensis }\end{array}$ & $\begin{array}{c}\text { Lycopersicum } \\
\text { esculentum }\end{array}$ & $\begin{array}{l}\text { Eruca } \\
\text { sativa }\end{array}$ \\
\hline \multirow{7}{*}{  } & 0 & $1,5 \mathrm{a}$ & $1,2 \mathrm{a}$ & $3,3 \mathrm{a}$ & $3,7 \mathrm{a}$ & $3,7 \mathrm{a}$ & $3,9 \mathrm{a}$ & $2,5 \mathrm{a}$ \\
\hline & 10 & $1,5 \mathrm{a}$ & $0,8 \mathrm{~b}$ & $3,4 \mathrm{a}$ & $2,9 \mathrm{a}$ & $2,5 \mathrm{a}$ & $3,4 \mathrm{a}$ & $1,1 \mathrm{~b}$ \\
\hline & 30 & $0,5 \mathrm{~b}$ & $0,1 \mathrm{c}$ & $1,0 \mathrm{~b}$ & $0,9 \mathrm{~b}$ & $0,6 \mathrm{~b}$ & $0,6 \mathrm{~b}$ & $0,7 \mathrm{~b}$ \\
\hline & 50 & $0,4 \mathrm{~b}$ & $0,0 \mathrm{c}$ & $0,9 \mathrm{~b}$ & $0,0 \mathrm{c}$ & $0,0 \mathrm{c}$ & $0,1 \mathrm{c}$ & $0,1 \mathrm{c}$ \\
\hline & 70 & $0,0 \mathrm{c}$ & $0,0 \mathrm{c}$ & $0,5 \mathrm{c}$ & $0,0 \mathrm{c}$ & $0,0 \mathrm{c}$ & $0,0 \mathrm{c}$ & $0,0 \mathrm{c}$ \\
\hline & 90 & $0,0 \mathrm{c}$ & $0,0 \mathrm{c}$ & $0,0 \mathrm{~d}$ & $0,0 \mathrm{c}$ & $0,0 \mathrm{c}$ & $0,0 \mathrm{c}$ & $0,0 \mathrm{c}$ \\
\hline & 100 & $0,0 \mathrm{c}$ & $0,0 \mathrm{c}$ & $0,0 \mathrm{~d}$ & $0,0 \mathrm{c}$ & $0,0 \mathrm{c}$ & $0,0 \mathrm{c}$ & $0,0 \mathrm{c}$ \\
\hline \multirow{7}{*}{ 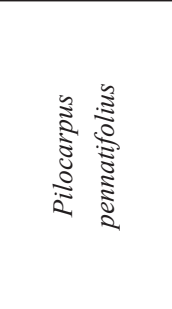 } & 0 & $2,6 \mathrm{a}$ & $2,6 \mathrm{a}$ & $2,8 \mathrm{a}$ & $3,4 \mathrm{a}$ & $3,1 \mathrm{a}$ & $3,5 \mathrm{a}$ & $2,1 \mathrm{a}$ \\
\hline & 10 & $2,4 \mathrm{a}$ & $2,3 \mathrm{a}$ & $2,9 \mathrm{a}$ & $3,4 \mathrm{a}$ & $3,3 \mathrm{a}$ & $3,0 \mathrm{ab}$ & $2,1 \mathrm{a}$ \\
\hline & 30 & $0,3 \mathrm{~b}$ & $2,3 \mathrm{a}$ & $0,5 \mathrm{~b}$ & $2,4 \mathrm{~b}$ & $1,3 \mathrm{~b}$ & $2,5 \mathrm{~b}$ & $0,7 \mathrm{~b}$ \\
\hline & 50 & $0,0 \mathrm{~b}$ & $1,4 \mathrm{~b}$ & $0,0 \mathrm{c}$ & $0,9 \mathrm{c}$ & $0,4 \mathrm{c}$ & $1,6 \mathrm{c}$ & $0,0 \mathrm{c}$ \\
\hline & 70 & $0,0 \mathrm{~b}$ & $0,5 \mathrm{c}$ & $0,0 \mathrm{c}$ & $0,4 \mathrm{~d}$ & $0,0 \mathrm{~d}$ & $1,2 \mathrm{c}$ & $0,0 \mathrm{c}$ \\
\hline & 90 & $0,0 \mathrm{~b}$ & $0,2 \mathrm{c}$ & $0,0 \mathrm{c}$ & $0,0 \mathrm{e}$ & $0,0 \mathrm{~d}$ & $0,0 \mathrm{~d}$ & $0,0 \mathrm{c}$ \\
\hline & 100 & $0,0 \mathrm{~b}$ & $0,2 \mathrm{c}$ & $0,0 \mathrm{c}$ & $0,0 \mathrm{e}$ & $0,0 \mathrm{~d}$ & $0,0 \mathrm{~d}$ & $0,0 \mathrm{c}$ \\
\hline \multirow{7}{*}{ 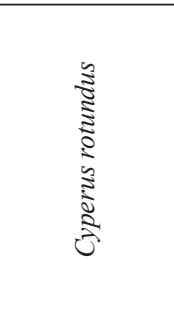 } & 0 & $4,5 \mathrm{a}$ & $4,2 \mathrm{a}$ & $3,6 \mathrm{a}$ & $4,7 \mathrm{a}$ & $4,2 \mathrm{a}$ & $9,0 \mathrm{a}$ & $2,7 \mathrm{a}$ \\
\hline & 10 & $4,5 \mathrm{a}$ & $3,5 \mathrm{a}$ & $3,6 \mathrm{a}$ & $4,6 \mathrm{a}$ & $4,2 \mathrm{a}$ & $9,0 \mathrm{a}$ & $2,6 \mathrm{~b}$ \\
\hline & 30 & $4,4 \mathrm{a}$ & $3,5 \mathrm{a}$ & $3,5 \mathrm{a}$ & $4,6 \mathrm{a}$ & $3,1 \mathrm{ab}$ & $8,4 \mathrm{a}$ & $2,3 \mathrm{~b}$ \\
\hline & 50 & $4,0 \mathrm{a}$ & $2,5 \mathrm{~b}$ & $3,0 \mathrm{a}$ & $3,0 \mathrm{ab}$ & $2,4 \mathrm{~b}$ & $8,0 \mathrm{a}$ & $2,4 \mathrm{~b}$ \\
\hline & 70 & $4,0 \mathrm{a}$ & $2,2 \mathrm{~b}$ & $1,3 \mathrm{~b}$ & $0,6 \mathrm{c}$ & $1,1 \mathrm{c}$ & $7,4 \mathrm{ab}$ & $2,9 \mathrm{~b}$ \\
\hline & 90 & $2,6 \mathrm{~b}$ & $0,5 \mathrm{c}$ & $1,3 \mathrm{~b}$ & $0,5 \mathrm{c}$ & $1,0 \mathrm{c}$ & $7,2 \mathrm{ab}$ & $2,2 \mathrm{~b}$ \\
\hline & 100 & $1,6 \mathrm{c}$ & $0,5 \mathrm{c}$ & $0,9 \mathrm{~b}$ & $0,5 \mathrm{c}$ & $0,2 \mathrm{~d}$ & $5,3 \mathrm{c}$ & $1,7 \mathrm{~b}$ \\
\hline \multirow{7}{*}{ 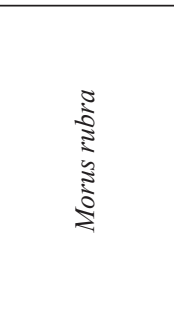 } & 0 & $0,7 \mathrm{a}$ & $3,0 \mathrm{a}$ & $3,2 \mathrm{a}$ & $3,6 \mathrm{a}$ & $3,4 \mathrm{a}$ & $3,6 \mathrm{a}$ & $1,2 \mathrm{a}$ \\
\hline & 10 & $0,7 \mathrm{a}$ & $3,0 \mathrm{a}$ & $3,1 \mathrm{a}$ & $2,8 \mathrm{ab}$ & $2,8 \mathrm{a}$ & $2,8 \mathrm{a}$ & $0,6 \mathrm{~b}$ \\
\hline & 30 & $0,3 \mathrm{~b}$ & $2,6 \mathrm{ab}$ & $2,8 \mathrm{a}$ & $2,8 \mathrm{ab}$ & $2,7 \mathrm{a}$ & $1,1 \mathrm{~b}$ & $0,3 \mathrm{c}$ \\
\hline & 50 & $0,2 \mathrm{~b}$ & $2,0 \mathrm{~b}$ & $1,4 \mathrm{~b}$ & $2,5 \mathrm{~b}$ & $1,3 \mathrm{~b}$ & $1,0 \mathrm{~b}$ & $0,0 \mathrm{c}$ \\
\hline & 70 & $0,0 \mathrm{~b}$ & $0,8 \mathrm{c}$ & $1,4 \mathrm{~b}$ & $0,5 \mathrm{c}$ & $0,5 \mathrm{c}$ & $0,2 \mathrm{c}$ & $0,0 \mathrm{c}$ \\
\hline & 90 & $0,0 \mathrm{~b}$ & $0,5 \mathrm{~cd}$ & $0,5 \mathrm{c}$ & $0,0 \mathrm{~d}$ & $0,4 \mathrm{c}$ & $0,2 \mathrm{c}$ & $0,0 \mathrm{c}$ \\
\hline & 100 & $0,0 \mathrm{~b}$ & $0,3 \mathrm{~d}$ & $0,4 \mathrm{c}$ & $0,0 \mathrm{~d}$ & $0,2 \mathrm{c}$ & $0,0 \mathrm{c}$ & $0,0 \mathrm{c}$ \\
\hline \multirow{7}{*}{ 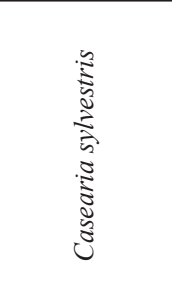 } & 0 & $2,1 \mathrm{a}$ & $4,4 \mathrm{a}$ & $2,4 \mathrm{a}$ & $3,5 \mathrm{a}$ & $4,3 \mathrm{a}$ & $5,1 \mathrm{a}$ & $2,6 \mathrm{a}$ \\
\hline & 10 & $2,0 \mathrm{a}$ & $4,0 \mathrm{a}$ & $2,3 \mathrm{a}$ & $2,6 a b$ & $2,7 \mathrm{~b}$ & $3,0 \mathrm{~b}$ & $2,6 \mathrm{a}$ \\
\hline & 30 & $1,7 \mathrm{ab}$ & $2,8 \mathrm{~b}$ & $1,6 \mathrm{ab}$ & $2,3 \mathrm{~b}$ & $2,6 \mathrm{~b}$ & $2,9 \mathrm{~b}$ & $2,4 \mathrm{a}$ \\
\hline & 50 & $1,3 \mathrm{ab}$ & $1,8 \mathrm{~b}$ & $1,1 \mathrm{~b}$ & $0,7 \mathrm{c}$ & $0,7 \mathrm{c}$ & $1,6 \mathrm{c}$ & $1,4 \mathrm{~b}$ \\
\hline & 70 & $0,7 \mathrm{bc}$ & $0,3 \mathrm{c}$ & $0,0 \mathrm{c}$ & $0,2 \mathrm{~d}$ & $0,0 \mathrm{~d}$ & $0,3 \mathrm{~d}$ & $0,4 \mathrm{c}$ \\
\hline & 90 & $0,4 \mathrm{c}$ & $0,1 \mathrm{c}$ & $0,0 \mathrm{c}$ & $0,0 \mathrm{~d}$ & $0,0 \mathrm{~d}$ & $0,3 \mathrm{~d}$ & $0,0 \mathrm{~d}$ \\
\hline & 100 & $0,2 \mathrm{c}$ & $0,0 \mathrm{c}$ & $0,0 \mathrm{c}$ & $0,0 \mathrm{~d}$ & $0,0 \mathrm{~d}$ & $0,3 \mathrm{~d}$ & $0,0 \mathrm{~d}$ \\
\hline \multirow{7}{*}{ 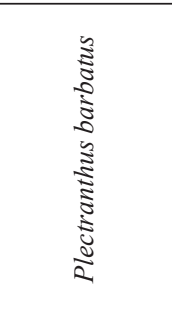 } & 0 & $0,7 \mathrm{a}$ & $1,5 \mathrm{a}$ & $1,4 \mathrm{a}$ & $3,6 \mathrm{a}$ & $1,5 \mathrm{a}$ & $4,8 \mathrm{a}$ & $2,7 \mathrm{a}$ \\
\hline & 10 & $0,7 \mathrm{a}$ & $1,4 \mathrm{a}$ & $1,2 \mathrm{a}$ & $3,5 \mathrm{a}$ & $1,5 \mathrm{a}$ & $4,3 \mathrm{a}$ & $2,8 \mathrm{a}$ \\
\hline & 30 & $0,0 \mathrm{~b}$ & $0,0 \mathrm{~b}$ & $0,2 \mathrm{~b}$ & $1,8 \mathrm{~b}$ & $0,2 \mathrm{~b}$ & $1,8 \mathrm{~b}$ & $0,2 \mathrm{~b}$ \\
\hline & 50 & $0,0 \mathrm{~b}$ & $0,0 \mathrm{~b}$ & $0,0 \mathrm{~b}$ & $0,0 \mathrm{c}$ & $0,0 \mathrm{~b}$ & $0,0 \mathrm{c}$ & $0,0 \mathrm{~b}$ \\
\hline & 70 & $0,0 \mathrm{~b}$ & $0,0 \mathrm{~b}$ & $0,0 \mathrm{~b}$ & $0,0 \mathrm{c}$ & $0,0 \mathrm{~b}$ & $0,0 \mathrm{c}$ & $0,0 \mathrm{~b}$ \\
\hline & 90 & $0,0 \mathrm{~b}$ & $0,0 \mathrm{~b}$ & $0,0 \mathrm{~b}$ & $0,0 \mathrm{c}$ & $0,0 \mathrm{~b}$ & $0,0 \mathrm{c}$ & $0,0 \mathrm{~b}$ \\
\hline & 100 & $0,0 \mathrm{~b}$ & $0,0 \mathrm{~b}$ & $0,0 \mathrm{~b}$ & $0,0 \mathrm{c}$ & $0,0 \mathrm{~b}$ & $0,0 \mathrm{c}$ & $0,0 \mathrm{~b}$ \\
\hline
\end{tabular}

Médias seguidas pelas mesmas letras nas colunas não diferem significativamente pelo teste Tukey a 5\% de probabilidade. 
Os extratos aquosos de M. rubra também demonstraram efeitos alelopáticos semelhantes, reduzindo o crescimento da raiz e da parte aérea de repolho, brócolis e tomate e, inibindo este parâmetro para alface, mostarda, couve e rúcula; o mesmo sendo observado para $C$. sylvestris, com redução no crescimento da parte aérea e sistema radicular de alface e tomate e inibição neste parâmetro para as duas estruturas vegetativas das demais hortaliças (repolho, brócolis, mostarda, couve e rúcula) (Tabelas 3 e 4).

Os extratos de folhas de C. rotundus foram menos efetivos quando comparado com os demais extratos foliares. Em linhas gerais, a folha é o órgão da planta mais ativo metabolicamente, sendo razoável que elas apresentem maior diversidade de aleloquímicos e maior efeito alelopático (RIBEIRO et al., 2009). Jacobi e Ferreira (1991) encontraram efeitos alelopáticos mais efetivos nos extratos de folhas de Mimosa bimucronata (DC) sobre alface (L. sativa), arroz (Oryza sativa L.), cenoura (Daucus carota L.), chicória (Cichorium endivia L.), couve (B. pekinensis), pepino (Cucumis sativus L.), repolho (B. oleracea) e tomate (L. esculentum). Aires et al. (2005) trabalhando com jurubeba (Solanum lycocarpum A. St.-Hil.) sobre gergelim (Sesamum indicum L.) também chegaram a essa conclusão. Ainda, Lousada et al. (2010) trabalhando com extratos hidroalcoólicos de $C$. rotundus sobre a emergência de picãopreto (Bidens pilosa L.), verificaram que não ocorreu efeito alelopático na germinação e no crescimento inicial de picão-preto. Entretanto, Sharma e Grupta (2007) verificaram que extratos alcoólicos de C. rotundus reduziram a germinação e o crescimento inicial de tomate e trigo (Triticum spp. L.) e Muniz et al. (2007) observaram redução da germinação de alface submetidas a diferentes concentrações de extratos aquosos de tubérculos de $C$. rotundus, não sendo observado, porém, influência dos extratos em relação à matéria seca. Essa redução e/ou inibição na germinação das hortaliças testadas foi atribuída à interferência, de substâncias presentes no extrato, na fase inicial do processo de germinação que envolve a degradação dos materiais de reserva das sementes (FERREIRA; BORGHETTI, 2004; LOUSADA et al., 2010).

A atividade biológica de um determinado aleloquímico depende tanto da concentração como do limite da resposta da espécie afetada. O limite de inibição para uma dada substância não é constante, porém está intimamente relacionada à sensibilidade da espécie receptora, aos processos das plantas e às condições ambientais (SOUZA FILHO et al., 2009). No presente estudo, os efeitos inibitórios estiveram positivamente associados à concentração dos extratos, ao órgão da planta e/ou espécie alelopática utilizada e às espécies receptoras, tanto quando se analisaram os efeitos sobre a germinação das sementes (Tabela 1), IVG (Tabela 2) quanto o crescimento inicial do sistema radicular como da parte aérea (Tabelas 3 e 4) de todas as hortaliças testadas. Reduções e inibições crescentes e alterações morfológicas ocorreram com o aumento da concentração, independente do extrato aquoso da espécie alelopática utilizada.

Em muitos estudos, observa-se que os efeitos alelopáticos são mais pronunciados sobre o crescimento inicial de uma plântula alvo que sobre a germinação, já que este último processo utiliza-se de reservas da própria semente (MIRÓ et al., 1998; JACOBI; FERREIRA, 1991; ÁQUILA, 2000; BORELLA; PASTORINI, 2009). Formagio et al. (2010) trabalhando com extratos metanólicos de cinco espécies de Annonaceae apontam que o desenvolvimento do hipocótilo de alface como a parte mais sensível aos efeitos alelopáticos e a germinação das sementes, a menos sensível, diferente do que foi relatado por Souza Filho et al. (2009) ao avaliar a atividade alelopática do óleo essencial de Ocimum americanum L. na germinação e desenvolvimento inicial de alface. Alterações nas curvas de germinação e índices de germinação calculados indicam, segundo Bewley e Black (1978) e Labouriau (1983), interferências nas reações metabólicas que culminam na germinação.

Observado no presente estudo e relatado por uma série de trabalhos, os extratos afetam mais severamente o crescimento inicial do sistema radicular quando comparado à parte aérea e com severas anormalidades (JACOBI; FERREIRA, 1991; PERIOTTO et al., 2004; MARASCHIN-SILVA; ÁQUILA, 2005; CARMO et al., 2007; ERCOLI et al., 2007; HOFFMANN et al., 2007; BORELLA; PASTORINI, 2009; SOUZA FILHO et al., 2009; GATTI et al., 2010; LOUSADA et al., 2010; SISODIA; SIDDIQUI, 2010; TUR et 
al., 2010), sendo que o efeito alelopático sobre a raiz, possivelmente, é decorrente do contato dessa estrutura com o extrato vegetal e, possivelmente, a presença de aleloquímicos esteja inibindo ou reduzindo atividades metabólicas e alterando a fisiologia da protusão radicular (CHUNG et al., 2001). Ainda, o crescimento da raiz é mais sensível aos efeitos fitotóxicos dos compostos em baixas concentrações quando comparado a germinação ou o crescimento do hipocótilo (PEREIRA et al., 2008). Concentrações moderadas promoveram atraso na germinação e concentrações altas podem inibir significativamente tanto no comprimento do hipocótilo quanto da radícula (CHOU, 2004). Ainda, os extratos causaram anormalidades, principalmente no sistema radicular, com o aparecimento de raízes primárias atrofiadas, defeituosas e ausentes em muitos casos (inibição total no crescimento).

O potencial alelopático das espécies, principalmente, as que são possivelmente, cultivadas em hortas e/ou com cultivo orgânico verificado no presente estudo pode ser uma estratégia para seu estabelecimento inicial, retardando o de outras plantas potencialmente competidoras (PIÑA-RODRIGUES; LOPES, 2001), por exemplo, hortaliças. A dominância de muitas espécies invasoras e/ou pioneiras também pode ser favorecida por outras características desse grupo ecológico, tais como produção de sementes pequenas e em grande quantidade, rápido crescimento e maturação e intolerância à sombra (FONTES, 1999; VÁLIO; SCARPA, 2001). Em suma, uma série de fatores pode contribuir para essa dominância, incluindo-se a alelopatia (MARASCHINSILVA; ÁQUILA, 2005). Muitas dessas espécies com potencial alelopático são cultivadas em hortas junto às hortaliças e, muitas vezes, em cultivos orgânicos e, se os efeitos fitotóxicos observados ocorrerem no campo, essas espécies poderão comprometer o desenvolvimento normal das hortaliças pela inibição do desenvolvimento radicial das plântulas.

O poder inibitório de extratos de plantas sobre outras plantas, verificada por meio de ensaios de laboratório, não indica necessariamente a ocorrência de efeitos alelopáticos sob condições de campo. A natureza química desses produtos é muito diversa e alguns só atuam quando em presença de outros, em combinações e proporções específicas, sendo difícil distinguir e identificar os efeitos individuais, devido à complexidade biológica do processo (BRUSTOLIN; CORTEZ, 2000), assim, novos bioensaios a campo deverá ser conduzidos com essas espécies para testar o efeito alelopático sobre as mesmas hortaliças.

Metabólitos secundários, com atuação alelopática, podem apresentar mecanismos de ação indiretos e diretos. Os efeitos indiretos incluem alterações nas propriedades e estado nutricional do solo, bem como nas populações e/ou atividades de microrganismos Já os efeitos diretos, que são mais estudados, incluem alterações no metabolismo vegetal, podendo afetar as características citológicas, os fitormônios, as membranas, a germinação, a absorção mineral, a respiração, a atividade enzimática, a divisão celular, entre outros (RICE, 1984; MARASCHIN-SILVA; ÁQUILA, 2005). Barbosa et al. (2008) e Wandscheer e Pastorini (2008) relatam que as respostas fisiológicas e morfológicas das sementes ou das plântulas à exposição a compostos alelopáticos são manifestações secundárias decorrentes de alterações moleculares e celulares, cujos mecanismos ainda permanecem obscuros. Da mesma forma, o perfil químico da maioria das espécies testadas em ensaios de alelopatia muitas vezes não está disponível na literatura (CARMO et al., 2007). Assim, a caracterização físico-química dos extratos vegetais utilizados nesses bioensaios é importante para que se possa concluir a respeito dos efeitos biológicos observados, confirmando alelopatia.

A presença de compostos do metabolismo vegetal pode levar à redução e/ou inibição no processo germinativo e crescimento inicial da parte aérea e do sistema radicular de espécies cultivadas em seu entorno, mas não se pode afirmar que a presença destes compostos ocasione efeito alelopático, visto a necessidade de testar as substâncias do metabolismo secundário, que podem tanto ter efeitos isoladamente, como podem interagir sinergicamente ou antagonicamente com outras substâncias.

Conforme os resultados obtidos nos bioensaios, pode-se concluir que das espécies invasoras e/ou pioneiras, $P$. barbatus e $C$. rotundous apresentaram maior e menor potencial alelopático, respectivamente, sendo 
que os extratos aquosos foliares de todas as espécies testadas causaram efeitos reducionais e/ou inibitórios, confirmado pelo atraso na germinação, no IVG e no crescimento inicial das espécies alvo utilizadas.

\section{Referências}

AQUILA, M. E. A. Efeito alelopático de Ilex paraguariensis A. St.-Hil. na germinação e crescimento inicial de Lactuca sativa L. Iheringia (Série Botânica), Porto Alegre, v. 53, p. 51-66, 2000.

AIRES, S. S.; FERREIRA, A. G.; BORGHETTI, F. Efeitos alelopáticos de folhas e frutos de Solanum lycocarpum A. St.-Hil. (Solanaceae) na germinação e crescimento de Sesamum indicum L. (Pedaliaceae) em solo sob três temperaturas. Acta Botanica Brasilica, Feira de Santana, v. 19, n. 1, p. 339-344, 2005.

BARBOSA, E. G.; PIVELlO, V. R.; MEIRELlES, S. T. Allelophathic evidence in Brachiaria decumbens and its potential to invade the Brazilian cerrados. Brazilian Archives of Biology and Technology, Curitiba, v. 51, n. 4, p. 825-831, 2008.

BEIGUELMAN, B. Curso prático de bioestatística. 5 ed. Ribeirão Preto: Funpec, 2002. 274 p.

BEWLEY, J. D.; BLACK, M. Physiology and biochemistry of seeds, in relation to germination. Berlim: Springer-Verlag, 1978. $306 \mathrm{p}$.

BORELLA, J.; PASTORINI, L. H. Influência alelopática de Phytolacca dioica L. na germinação e crescimento inicial de tomate e picão-preto. Biotemas, Florianópolis, v. 22, n. 3, p. 67-75, 2009.

BRASIL. Ministério da Agricultura e Reforma Agrária. Regras para análise de sementes. Brasília: SNDA/DNDV/CLAV, 1992. $360 \mathrm{p}$.

BRUSTOLIN, A.; CORTEZ, D. A. G. Avaliação da atividade moluscicida da Gymnema sylvestre R. BR. Acta Scientiarum, Londrina, v. 22, n. 2, p. 605-608, 2000.

BUCHANAN, B. B.; GRUISSEM, W.; JONES, R. L. Biochemistry \& molecular biology of plants. Maryland: American Society of Plant Physiologists, 2000. 1367 p.

CARMO, F. M. S.; BORGES, E. E. L.; TAKAKI, M. Alelopatia de extratos aquosos de canela-sassafrás (Ocotea odorifera (Vell.) Rohwer). Acta Botanica Brasilica, Feira de Santana, v. 21, n. 3, p. 697-705, 2007.

CENTENARO, C.; CORRÊA, L. G. P.; KARAS, M. J.; VIRTUOSO, S.; DIAS, J. F. G.; MIGUEL, O. G.; MIGUEL, M. D. Contribuição ao estudo alelopático de Erythrina velutina Willd., Fabaceae. Brazilian Journal of Pharmacognosy, Curitiba, v. 19, n. 1, p. 304-308, 2009.

CHIAPUSIO, G.; SÁNCHEZ, A. M.; REIGOSA, M. J.; GONZÁLEZ, L.; PELLISSIER, F. Do germination indices adequately reflect allelochemical effects on the germination process? Journal of Chemical Ecology, Tampa, v. 23, n. 11, p. 2445-2453, 1997.

CHOU, S. U. Allelopathic and autotoxic effecgts of alfafa plant and soil extracts. Korean Journal of Crop Science, Seoul, v. 49, n. 1, p. 7-11, 2004.
CHUNG, I. M.; AHN, L. K.; YUN, S. J. Assesment of allelopathic potential of barnyard grass (Echinochloa crus-gall) on rice (Oriza sativa L.) cultivars. Crop Protection, Pullman, v. 20, n. 10, p. $921-$ 928, 2001.

DIAS, J. F. G.; CÍRIO, G. M.; MIGUEL, M. D.; MIGUEL, O. G. Contribuição ao estudo alelopático de Maytenus ilicifolia Mart. Ex Reiss., Celastraceae. Revista Brasileira de Farmacognosia, Curitiba, v. 15, n. 3, p. 220-223, 2005.

ERCOLI, L.; MASONI, A.; PAMPANA, S.; ARDUINI, I. Allelopathic effects of rye, brown mustard and hairyn vetch on redroot pigweed, common lambsquarter and knotweed. Allelopathy Journal, New York, v. 19, n. 1, p. 249-256, 2007.

FERREIRA, A. G.; ÁQUILA, M. E. A. Alelopatia: uma área emergente da ecofisiologia. Revista Brasileira de Fisiologia Vegetal, Campinas, v. 12, p. 175-204, 2000.

FERREIRA, A. G.; BORGUETTI, F. 2004. Germinação: do básico ao aplicado. Porto Alegre: Artmed, 2004. 323 p.

FONTES, M. A. L. Padrões alométricos em espécies arbóreas pioneiras tropicais. Scientia Florestalis, Piracicaba, v. 55, p. 7987, 1999.

FORMAGIO, A. S. N.; MASETTO, T. E.; BALDIVIA, D. S.; VIEIRA, M. C.; ZARATE, N. A. H.; PEREIRA, Z. V. Potencial alelopático de cinco espécies da família Annonaceae. Revista Brasileira de Biociências, Porto Alegre, v. 8, n. 4, p. 349-354, 2010.

JACOBI, U. S.; FERREIRA, A. G. Efeitos alelopáticos de Mimosa bimucronata (DC) OK. sobre espécies cultivadas. Pesquisa Agropecuária Brasileira, Brasília, v. 26, n.7 , p. 935-943, 1991.

GATTI, A. B.; FERREIRA, A. G.; ARDUIN, M.; PEREZ, S. C. G. A. Allelopathic effects of aqueous extracts of Artistolochia esperanzae O.Kuntze on development of Sesamum indicum L. seedlings. Acta Botanica Brasilica, Feira de Santana, v. 24, n. 3 , p. 454-461, 2010.

HOFFMANN, C. E. F.; NEVES, L. A. S.; BASTOS, C. F.; WALLAU, G. L. 2007. Atividade alelopática de Nerium oleander L. e Dieffenbachia picta schott em sementes de Lactuca sativa L. e Bidens pilosa L. Revista de Ciências Agroveterinárias, Lages, v. 6, n. 1, p. 11-21, 2007.

KATO-NOGUCHI, H.; INO, T. Assessment of allelopathic potential of root exudate of rice seedlings. Biologia Plantarum, Praha, v. 44, n. 4, p. 635-638, 2001.

LABOURIAU, L. F. G. A germinação das sementes. Washington: Departamento de Assuntos Científicos e Tecnológicos da Secretaria Geral da Organização dos Estados Americanos. (Série Biologia, 24), 1983. $174 \mathrm{p}$

LOUSADA, L. L.; LEMOS, G. C. S.; FREITAS, S. P.; SILVA, R. M.; ESTEVES, B. S. Alelopatia de extratos hidro-alcóolicos de Cyperus rotundus L. sobre emergência de Bidens pilosa L. In: CONGRESSO BRASILEIRO DA CIÊNCIA DAS PLANTAS DANINHAS, 27, 2010, Ribeirão Preto. Anais...Ribeirão Preto: SBCPD, 2010. p. 3329-3331.

MACEDO, F. M.; MARTINS, G. T.; RODRIGUES, C. G.; OLIVEIRA, D. A. 2007. Triagem fitoquímica do barbatimão (Stryphnodendron adstringens (Mart.) Coville). Revista Brasileira de Biociências, Porto Alegre, v. 5, p. 1166-1168, 2007. 
MAGUIRE, J. D. Speed of germination-aid in selection evaluation for seedling emergence and vigour. Crop Science, Madison, v. 2, n. 2, p. 176-177, 1962.

MARASCHIN-SILVA, F.; ÁQUILA, M. E. A. Potencial alelopático de Dodonaea viscosa (L.) Jacq. Iheringia: Série Botânica, Porto Alegre, v. 60, n. 1, p. 91-98, 2005.

MIRÓ, C. P.; FERREIRA, A. G.; ÁQUILA, M. E. A. Alelopaita de frutos de erva-mate (Ilex paraguariensis) no desenvolvimento do milho. Pesquisa Agropecuária Brasileira, Brasília, v. 33, n. 8, p. 61-270, 1998.

MUNIZ, F. R.; CARDOSO, M. D. G.; PINHO, E. V. R. V. P.; VILELA, M. Qualidade de sementes de milho, feijão, soja e alface na presença de extratos de tiririca. Revista Brasileira de Sementes, Londrina, v. 29, n. 2, p. 195-204, 2007.

PEREIRA, B. F.; SBRISSIA, A. F.; SERRAT, B. M. Alelopatia intra-específica de extratos aquosos de folhas e raízes de alfafa na germinação e no crescimento inicial de plântulas de dois materiais de alfafa: crioulo e melhorado. Ciência Rural, Santa Maria, v. 38, n. 2, p. 561-564, 2008.

PERIOTTO, F.; PEREZ, S. C. J. G. A.; LIMA, M. I. S. Efeito alelopático de Andira humilis Mart. ex Benth na germinação e no crescimento de Lactuca sativa L. e Raphanus sativus L. Acta Botanica Brasilica, Feira de Santana, v. 18, n. 3, p. 425-430, 2004. PIÑA-RODRIGUES, F. C. M.; LOPES, B. M. Potencial alelopático de Mimosa caesalpinaefolia Benth sobre sementes de Tabebuia alba (Cham.) Sandw. Floresta e Ambiente, Seropédica, v. 8, n. 1, p. 130-136, 2001.

RIBEIRO, J. P.; MATSUMOTO, R. S.; TADAO, L. K.; VOLTARELLI, V. M.; LIMA, M. I. S. Efeitos alelopáticos de extratos aquosos de Crinum americanum L. Revista Brasileira de Botânica, São Paulo, v. 32, n. 1, p. 183-188, 2009.

RICE, E. L. Allelopathy. 2 ed. New York, Academic Press, 1984. $422 \mathrm{p}$.

SARTOR, L. R.; ADAMI, P. F.; CHINI, N.; MARTIN, T. N.; MARCHESE, J. A.; SOARES, A. B. Alelopatia de acículas de Pinus taeda na germinação e no desenvolvimento de plântulas de Avena strigosa. Ciência Rural, Santa Maria, v. 39, n. 6, p. $1653-$ 1659, 2009.
SHARMA, R.; GRUPTA, R. Cyperus rotundus extract inhibits acetylcholinesterase activity from animal and plants as well as inhibits germination and seedling growth in wheat and tomato. Life Sciences, Elmsford, v. 80, n. 24-25, p. 2389-2392, 2007.

SILVA, J. da; FORTE, A. M. T.; GOMES, F. M.; PINTO, T. T.; BONAMIGO, G. O. T.; BOIAGO, N. P. Alelopatia Camelina sativa Boiss. (Brassicaceae) sobre a germinação e o desenvolvimento inicial de Bidens pilosa L. e de Glycine max (L.) Merr. Biotemas, Florianópolis, v. 24, n. 4, p. 17-24, 2011.

SISODIA, S.; SIDDIQUI, M. B. Allelopathic effect by aqueous extracts of different parts of Croton bonplandianum Baill. on some crop and weed plants. Journal of Agricultural Extension and Rural Development, Washington, v. 2, n. 1, p. 22-28, 2010.

SOUZA FILHO, A. P. S.; ALVES, S. M. Alelopatia: princípios básicos e aspectos gerais. Belém: Embrapa Amazônia Oriental, 2002. 260 p.

SOUZA FILHO, A. P. S.; GUILHON, G. M. S. P.; ZOGHBI, M. G. B.; CUNHA, R. L. Análise comparativa do potencial alelopático de extrato hidroalcoólico e do óleo essencial de folhas de cipó d'alho (Bignoniaceae). Planta Daninha, Viçosa, v. 27, n. 4, p. 647-653, 2009.

TUR, C. M.; BORELlA, J.; PASTORINI, L. H. Alelopatia de extratos aquosos de Duranta repens sobre a germinação e crescimento inicial de Lactuca sativa e Lycopersicum esculentum. Biotemas, Florianópolis, n. 23, v. 2, p. 13-22, 2010.

VÁLIO, I. F.; SCARPA, F. M. Germination of seeds of tropical pioneer species under controlled and natural conditions. Revista Brasileira de Botânica, São Paulo, v. 24, n. 3, p. 697-701, 2001.

WANDSCHEER, A. C. D.; PASTORINI, L. H. Interferência alelopática de Raphanus raphanistrum L. sobre a germinação de Lactuca sativa L. e Solanum lycopersicon L. Ciência Rural, Santa Maria, v. 38, n. 4, p. 949-953, 2008. 